\title{
Adsorption of 1,4-Dioxane from Aqueous Solutions onto Various Activated Carbons
}

\author{
Tomoko FUKUHARA*, Satoshi IWASAKI*, Takahiro HASEGAWA*, Kazuhiro \\ ISHIHARA**, Manabu FUJIWARA***, Ikuo ABE**** \\ * Osaka Municipal Technical Research Institute, 1-6-50 Morinomiya, Joto-ku, Osaka \\ 536-8553, Japan \\ **Futamura Chemical Co. Ltd., 2-2-62 Mikado-cho, Minokamo-shi, Gifu 505-0024, Japan \\ ***Ryukoku University, Faculty of Science and Technology, 1-5 Yokotani, Seta Oe-cho, Otsu, \\ Shiga 520-2194, Japan \\ ****Eco-Carbon Laboratory, 4-385 Funaocho-nishi, Nishi-ku, Sakai, Osaka 592-8342, Japan
}

\begin{abstract}
The behavior of the adsorption of 1,4-dioxane (DOX) in water onto eight different activated carbons (ACs) was studied. All adsorption isotherms obtained using batch-type adsorption measurements, were found to fit a Freundlich equation. The amount adsorbed at an equilibrium concentration of $50 \mu \mathrm{g} / \mathrm{L}\left(\mathrm{q}_{50}\right)$ was obtained, and its correlation with microporosity and chemical properties of each AC was examined. The AC prepared from sawdust by direct activation adsorbed the most DOX $(410 \mu \mathrm{g} / \mathrm{g})$, while adsorption in the other ACs were in the range of 4.3 $71.1 \mu \mathrm{g} / \mathrm{g}$. No practical influence of specific surface area on the adsorption of DOX was found. We observed that $\log \mathrm{q}_{50}$ mostly decreased linearly with an increase in mean pore diameter. The concentrations of acidic surface oxides and nitrogen in the ACs affected the hydrophilicity of the adsorbent and impaired $\mathrm{q}_{50}$. It was assumed that the main factor for the adsorption of DOX at trace concentration in water was surface chemistry rather than the microporosity of AC.
\end{abstract}

Keywords: activated carbon, adsorption, 1,4-dioxane

\section{INTRDUCTION}

The primary applications of 1,4-dioxane (DOX) include its use as an industrial solvent for paints, a surface-treating agent for artificial leather, and as a stabilizer for organochlorine solvents. Large-scale consumption of the chemical leads to environmental pollution. Because of its carcinogenicity, the 2003 World Health Organization (WHO) guidelines for drinking-water quality have recommended a maximum DOX concentration of $0.05 \mathrm{mg} / \mathrm{L}$. In Japan, the DOX standard value for drinking water was set at $0.05 \mathrm{mg} / \mathrm{L}$ in 2004 , and the same value was established as an environmental quality standard for aquatic environments in 2009. Technology to reduce DOX concentrations in water down to several tenths of a microgram per liter is needed to minimize the effects of DOX on human health.

Activated carbon (AC) is widely used for the removal of hydrophobic organic compounds in water. The operation of AC adsorption processes is generally easy, and their performance is reliable. It can be applied to various scales of a treatment plant. In addition, ensuring safety is easier because target compounds are removed by mass transfer. However, it is known that DOX is a hydrophilic compound and is miscible with water in all proportions. The fact suggests that the adsorbability of DOX onto AC is qualitatively low. Therefore, no concrete data for DOX adsorption onto AC has been reported to date. Exploring the adsorption behavior is useful in developing effective treatment technologies for DOX removal. In general, the adsorptive properties of

Address correspondence to Tomoko Fukuhara, Osaka Municipal Technical Research Institute,

Email: fukuhara@omtri.or.jp

Received September 14, 2010, Accepted April 29, 2011. 
hydrophobic porous adsorbents are dependent mainly on their specific surface area and pore diameter (Abe et al., 1983a). In addition, chemical functional groups on the surface of AC may have an influence on the adsorbent-adsorbate and adsorbent-water interaction.

This study aimed to investigate the adsorption of DOX in water onto various ACs and to explore the relationship of microporosity and chemical properties of ACs with the adsorbability of DOX. The adsorption isotherms were obtained by conducting measurements of single-component adsorption onto eight kinds of ACs. The effects of the above-mentioned properties of ACs on the adsorption of $0.05 \mathrm{mg} / \mathrm{L}$ of DOX and the mechanism of DOX adsorption are discussed.

\section{EXPERIMENTAL}

\section{Activated Carbon}

Table 1 shows the properties of the ACs examined. The ACs were prepared from various sources: AC-A1 and AC-A2 from coconut shell, AC-B1 and AC-B2 from phenol resin, $\mathrm{AC}-\mathrm{C} 1, \mathrm{AC}-\mathrm{C} 2$, and $\mathrm{AC}-\mathrm{C} 3$ from coal, and AC-D from sawdust by direct activation in a rotary kiln, without a carbonization process. This manufacturing process (activated carbon and its manufacturing procedure) is registered as a patent (JP $4142341 \mathrm{~B}$ ). Some of the ACs (AC-A1, AC-A2, AC-B1, AC-B2, AC-C1, and AC-D) were commercial varieties supplied by Futamura Chemical Co., Ltd. (Nagoya, Japan). All ACs except the powdered types (AC-C3 and AC-D) were ground and passed through a $75 \mu \mathrm{m}$ sieve. The powders were dried at $388 \mathrm{~K}$ for $3 \mathrm{~h}$ and kept in a desiccator containing silica gel.

\section{Measurement of physical and chemical properties of ACs}

The specific surface area $(\mathrm{S})$, pore volume $\left(\mathrm{V}_{\mathrm{N} 2}\right)$, and mean pore diameter $(\mathrm{d})$ of the ACs were determined from nitrogen adsorption isotherms using a Nihon Bell Belsorp 18PLUS (Osaka, Japan). The values of $\mathrm{S}, \mathrm{V}_{\mathrm{N} 2}$, and $\mathrm{d}$ were evaluated using a typical numerical analysis as follows (Iwasaki et al., 2002). The value of $\mathrm{S}$ was calculated from BET plots in the relative pressure range of $0.01-0.1$. The value of $\mathrm{V}_{\mathrm{N} 2}$ was determined from the amount of nitrogen adsorbed at the relative pressure of 0.931 , and was used to estimate the total volume of pores with diameter less than $30 \mathrm{~nm}$. The value of $\mathrm{d}$ was calculated using the equation $\mathrm{d}=4 \mathrm{~V}_{\mathrm{N} 2} / \mathrm{S}$, with the pore system being assumed to consist of uniform cylindrical nonintersecting capillaries.

Table 1 - Properties of activated carbons examined

\begin{tabular}{|c|c|c|c|c|c|c|c|c|}
\hline \multirow{2}{*}{$\begin{array}{c}\text { Activated } \\
\text { carbon }\end{array}$} & \multirow{2}{*}{$\begin{array}{c}\text { Commercial } \\
\text { name }\end{array}$} & \multirow{2}{*}{ Raw material } & \multirow{2}{*}{ Form } & \multicolumn{3}{|c|}{ Microporosity } & \multirow{2}{*}{\begin{tabular}{|c}
$\begin{array}{c}\text { Acidic surface } \\
\text { oxide }\end{array}$ \\
$\mathrm{C}_{\text {aso }}$ \\
(meq/g)
\end{tabular}} & \multirow{2}{*}{$\begin{array}{l}\text { Nitroger } \\
\text { content } \\
C_{n}(\%)\end{array}$} \\
\hline & & & & $\mathrm{S}\left(\mathrm{m}^{2} / \mathrm{g}\right)$ & $V_{N_{2}}(\mathrm{~mL} / \mathrm{g})$ & $\mathrm{d}(\mathrm{nm})$ & & \\
\hline AC-A1 & Taiko CW830A & Coconut shell & Granular & 1060 & 0.47 & 1.78 & 0.218 & 0.18 \\
\hline AC-A2 & Taiko CW830AZ & Coconut shell & Granular & 1810 & 0.89 & 1.96 & 0.251 & 0.18 \\
\hline AC-B1 & Taiko FE10 & Phenol resin & Fibrous & 1162 & 0.47 & 1.61 & 0.206 & 0.15 \\
\hline AC-B2 & Taiko FE15 & Phenol resin & Fibrous & 1628 & 0.69 & 1.69 & 0.186 & 0.16 \\
\hline$A C-C 1$ & Taiko GL130A & Coal & Granular & 1000 & 0.50 & 2.01 & 0.144 & 0.33 \\
\hline AC-C2 & - & Coal & Granular & 1102 & 0.53 & 1.93 & 0.198 & 0.26 \\
\hline $\mathrm{AC}-\mathrm{C} 3$ & - & Coal & Powdered & 1187 & 0.72 & 2.44 & 0.371 & 0.29 \\
\hline$A C-D$ & Taiko W & Sawdust & Powdered & 983 & 0.49 & 1.98 & 0.091 & 0.08 \\
\hline
\end{tabular}

$\mathrm{S}$ : specific surface area; $\mathrm{V}_{\mathrm{N} 2}$ : pore volume; $\mathrm{d}$ : mean pore diameter; 
The concentration of acidic surface oxides $\left(\mathrm{C}_{\text {aso }}\right)$ in the ACs was obtained by the usual depletion technique that employs a reaction with excess aqueous $\mathrm{NaOH}$. Possible structures of acidic surface oxides have been suggested by many studies (Boehm, 1994; Bansal and Goyal, 2005). A pulverized carbon sample $(1.0 \mathrm{~g})$ was placed in $50 \mathrm{~mL}$ of $0.05 \mathrm{~mol} / \mathrm{L} \mathrm{NaOH}$ solution, sealed, and allowed to equilibrate by shaking for $24 \mathrm{~h}$ at ambient temperature. A portion of the solution was filtered and titrated with standard $0.05 \mathrm{~mol} / \mathrm{L} \mathrm{HCl}$ solution. The total number of milliequivalents of acid oxides per gram of sample, $\mathrm{C}_{\text {aso }}$ (meq/g), was determined.

Measurement of the nitrogen content $\left(\mathrm{C}_{\mathrm{n}}(\%)\right)$ of the ACs was carried out using an automatic elementary analyzer (Model EA1110, CE Instruments Ltd., UK).

\section{Measurement of DOX concentration}

A commercial reagent of DOX was obtained from Tokyo Kasei Co. Ltd. (Tokyo, Japan). The concentration of DOX in water was determined by solid phase microextraction (SPME). The SPME fiber assembly of $75 \mu \mathrm{m}$ Carboxen ${ }^{\mathrm{TM}}$-PDMS was installed with a manual holder (SUPELCO Inc., PA, USA). The fiber was exposed to the water sample, which was sealed in a glass vial, for 10 min at ambient temperature via a rubber septum. The fiber was placed at an injection port, and DOX trapped on the fiber was desorbed by heat and injected directly into a GC/MS instrument (Automass SUN200, JEOL, Japan). The linearity in the measurement range was confirmed in advance.

\section{Measurement of the adsorption isotherms of DOX onto ACs}

Batch-type adsorption measurements were carried out as follows. A $50 \mathrm{~mL}$ aliquot of the aqueous DOX solution and various quantities of $\mathrm{AC}$ were placed in a glass vial and sealed using Teflon film, a rubber septum, and an aluminum cap. The vials were shaken for $16-24 \mathrm{~h}$ at $296 \mathrm{~K}$ to achieve adsorption equilibrium. The volume of AC was varied over a range of $0.1-40 \mathrm{mg} / \mathrm{L}$. After shaking and settling, the equilibrium concentration of DOX was measured by SPME as mentioned above.

For each vial, the amount of DOX adsorbed was calculated according to the following equation:

$$
\mathrm{q}=\mathrm{V}\left(\mathrm{C}_{0}-\mathrm{C}_{\mathrm{e}}\right) / \mathrm{w}
$$

where $\mathrm{q}$ is the amount of DOX adsorbed, $\mathrm{w}$ is the dose of $\mathrm{AC}, \mathrm{V}$ is the volume of solution, and $\mathrm{C}_{0}$ and $\mathrm{C}_{\mathrm{e}}$ are the pre- and post-adsorption concentrations of DOX, respectively. The corresponding units of measure are $\mathrm{q}(\mu \mathrm{g} / \mathrm{g}), \mathrm{w}(\mathrm{mg}), \mathrm{V}(\mathrm{mL}), \mathrm{C}_{0}$ $(\mu \mathrm{g} / \mathrm{L})$, and $\mathrm{C}_{\mathrm{e}}(\mu \mathrm{g} / \mathrm{L})$.

\section{RESULTS AND DISCUSSION}

\section{Adsorption isotherms of aqueous DOX}

The adsorption isotherms of aqueous DOX onto eight kinds of ACs at $296 \mathrm{~K}$ were obtained using batch-type adsorption measurements. The data were used to obtain best-fit estimates of parameters in the Freundlich equation:

$$
\log q=\log K+(1 / n) \log C_{e}
$$


where $\mathrm{K}$ and $1 / \mathrm{n}$ are Freundlich adsorption constants. The DOX adsorption isotherms are shown in Fig. 1. The estimates of $\mathrm{K}, 1 / \mathrm{n}$ and the amount adsorbed at the equilibrium concentration of $50 \mu \mathrm{g} / \mathrm{L}\left(\mathrm{q}_{50}\right)$ are summarized in Table 2 .

All adsorption isotherms obtained were found to fit a Freundlich equation. We found that AC-D adsorbed a markedly large amount $\left(\mathrm{q}_{50}=410 \mu \mathrm{g} / \mathrm{g}\right)$. For other ACs, $\mathrm{q}_{50}$ was in the range of $4.3-71.1 \mu \mathrm{g} / \mathrm{g}$; thus, $\mathrm{q}_{50}$ for $\mathrm{AC}-\mathrm{D}$ was approximately 18 times as large as that for $\mathrm{AC}-\mathrm{C} 1$, a commercial variety commonly used in water purification. The amounts of DOX adsorbed onto ACs observed in this study were less than those of other various hydrophobic organic compounds in other studies (Dobbs and Cohen, 1980).

The contribution of individual atoms to the adsorption process of 178 organic compounds was evaluated (Abe et al., 1985). The contribution of carbon atoms is positive, while that of oxygen atoms is negative. The hydrophobicity of the molecule increases as the number of carbon atoms increases, and the solubility in water decreases. The oxygen atom forms hydrophilic functional groups such as hydroxyl or ether groups. By increasing these hydrophilic groups in the molecule, water solubility is increased and adsorbability is decreased (Abe et al., 1983b). According to these reports, DOX,

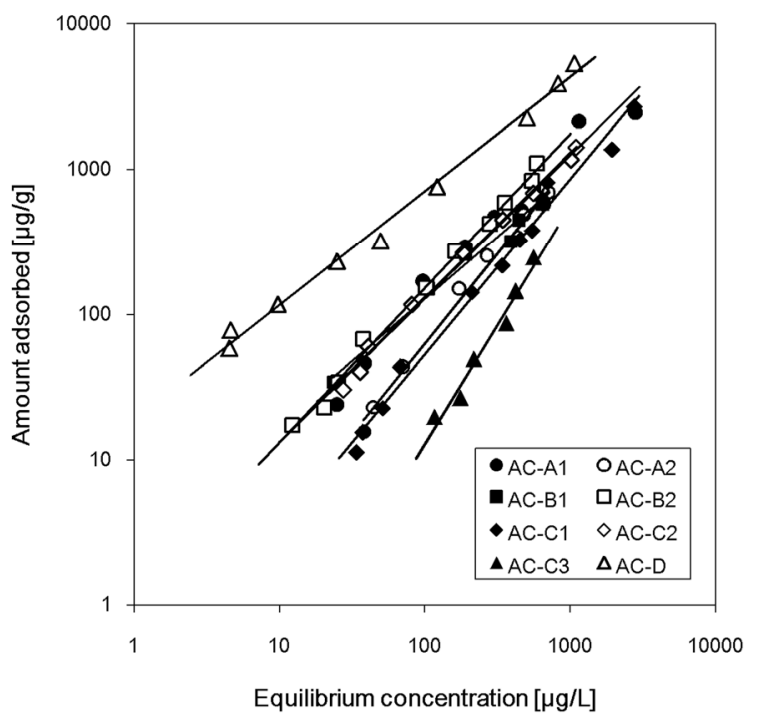

Fig. 1 - Adsorption isothems of 1,4-dioxane onto activated carbons in water (296 K).

Table 2 - Freundlich adsorption constants on 1,4-dioxane onto ACs in water

\begin{tabular}{|c|c|c|c|c|}
\hline \multirow{2}{*}{$\begin{array}{l}\text { Activated } \\
\text { carbon }\end{array}$} & \multicolumn{2}{|c|}{ Freundlich constants( $\left.{ }^{*}\right)$} & \multirow{2}{*}{$\begin{array}{c}\text { Correlation coefficient } \\
\mathrm{R}\end{array}$} & \multirow{2}{*}{$\begin{array}{l}q_{50}\left(^{* *}\right. \\
(\mu \mathrm{g} / \mathrm{g})\end{array}$} \\
\hline & $\mathrm{K}$ & $1 / n$ & & \\
\hline AC-A1 & 1.38 & 0.986 & 0.983 & 65.2 \\
\hline AC-A2 & 0.202 & 1.25 & 0.995 & 26.9 \\
\hline AC-B1 & 2.44 & 0.862 & 0.986 & 71.1 \\
\hline$A C-B 2$ & 1.16 & 1.06 & 0.997 & 73 \\
\hline $\mathrm{AC}-\mathrm{C} 1$ & 0.21 & 1.2 & 0.994 & 22.9 \\
\hline $\mathrm{AC}-\mathrm{C} 2$ & 1.31 & 0.996 & 0.997 & 64.4 \\
\hline $\mathrm{AC}-\mathrm{C} 3$ & 0.0073 & 1.63 & 0.985 & 4.3 \\
\hline$A C-D$ & 19 & 0.785 & 0.997 & 410 \\
\hline
\end{tabular}


which has four carbon atoms and two oxygen atoms, is considerably affected by hydrophilicity and weakly affected by hydrophobicity. The molecules of DOX are, for the most part, stable among water molecules. Therefore, the affinity between the adsorbate (DOX) and the solvent (water) is considerably strong for DOX to be separated from water onto the AC surface.

The relationship between the Freundlich constant $1 / \mathrm{n}$ and $\log \mathrm{q}_{50}$ is shown in Fig. 2. A least squares fit to the relationship gave the following equation:

$$
\log \mathrm{q}_{50}=-2.0(1 / \mathrm{n})+3.9 \quad(\text { correlation coefficient, } \mathrm{R}=-0.948)
$$

A strong relationship between $(1 / \mathrm{n})$ and $\log \mathrm{q}_{50}$ was thus observed for DOX adsorption onto ACs. The Freundlich parameter $1 / \mathrm{n}$ was related to the affinity between the adsorbate and the adsorbent (Furuya et al., 1997). It was presumed that the strength of the affinity between DOX and AC is reflected in the amount of adsorbed DOX.

\section{Effects of microporosity of the activated carbons on DOX adsorption}

The effects of $\mathrm{S}$ and $\mathrm{d}$ (which was calculated from $\mathrm{S}$ and $\mathrm{V}_{\mathrm{N} 2}$ ) on DOX adsorption were examined. A least squares fit between $\mathrm{S}$ and $\log \mathrm{q}_{50}$ gave the following equation:

$$
\log \mathrm{q}_{50}=-3.6 \times 10^{-4} \mathrm{~S}+2.1 \quad \text { (correlation coefficient, } \mathrm{R}=-0.193 \text { ) }
$$

Thus, there was barely any correlation between $\mathrm{S}$ and $\log \mathrm{q}_{50}$. No practical influence of $\mathrm{S}$ on the adsorption of DOX was found at low concentrations such as $50 \mu \mathrm{g} / \mathrm{L}$.

A least squares fit between $d$ and $\log q_{50}$ yielded the following equation:

$$
\log \mathrm{q}_{50}=-1.4 \mathrm{~d}+4.4 \quad \text { (correlation coefficient, } \mathrm{R}=-0.637 \text { ) }
$$

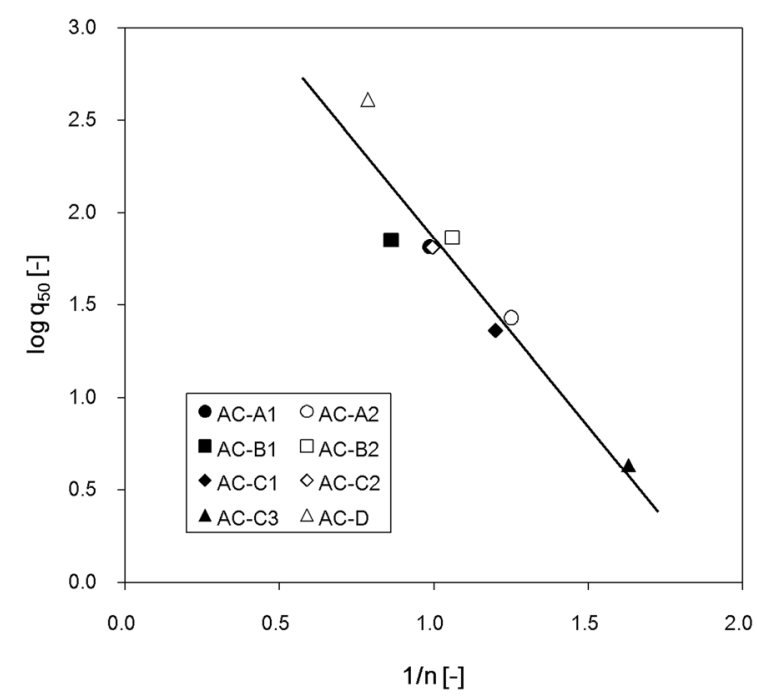

Fig. 2 - Correlation between the Freundlich constant $1 / n$ and the amount of 1,4-dioxane adsorbed on ACs at $50 \mu \mathrm{g} / \mathrm{L}\left(\mathrm{q}_{50}\right)$. Solid line shows Eq. (3). 
The relationship and Eq. (5) are shown in Fig. 3. It is apparent that $\log \mathrm{q}_{50}$ decreases linearly with an increase in $\mathrm{d}$; nonetheless, the correlation coefficient $\mathrm{R}$ was no more than -0.637 . Recalculated correlation coefficients were considerably strong, except for AC-D $(\mathrm{R}=-0.946)$.

In general, the adsorptive properties of hydrophobic porous adsorbents are mainly dependent on their pore size distributions. Specific surface area affects the adsorption capacity, and pore diameter affects the adsorption force. In contrast to usual observations, the results in this part of this study show no influence of $\mathrm{S}$ on $\log \mathrm{q}_{50}$. In general, adsorption onto $\mathrm{AC}$ is mainly based on the London dispersion force, which is part of the van der Waals' force (Noll et al., 1992). The closer the location of the adsorbate in the pores to the surrounding pore walls, the higher the adsorption force. Adsorption force increases with decreasing pore size (Abe et al., 1983a; Li et al., 2002). A similar result was obtained in the case of chloroform adsorption at $30 \mu \mathrm{g} / \mathrm{L}$ in water (Abe et al., 2001); i.e., the effect of adsorption force was greater than that of the specific surface area. Although DOX is a hydrophilic organic compound, the strong correlation between $\log \mathrm{q}_{50}$ and $\mathrm{d}$, except for AC-D, suggests that the adsorption force between DOX and $\mathrm{AC}$ is mainly derived from the London dispersion force, similar to that causing the adsorption of common hydrophobic compounds.

\section{Effect of chemical properties of activated carbons on DOX adsorption}

To analyze the effects of chemical properties of ACs on DOX adsorption, $C_{\text {aso }}$ and $C_{n}$ were examined.

A least squares fit between $\mathrm{C}_{\mathrm{aso}}$ and $\log \mathrm{q}_{50}$ gave the following equation:

$$
\log \mathrm{q}_{50}=-5.8 \mathrm{C}_{\mathrm{aso}}+2.9 \quad \text { (correlation coefficient, } \mathrm{R}=-0.848 \text { ) }
$$

The relationship and Eq. (6) are shown in Fig. 4. The value of the correlation coefficient

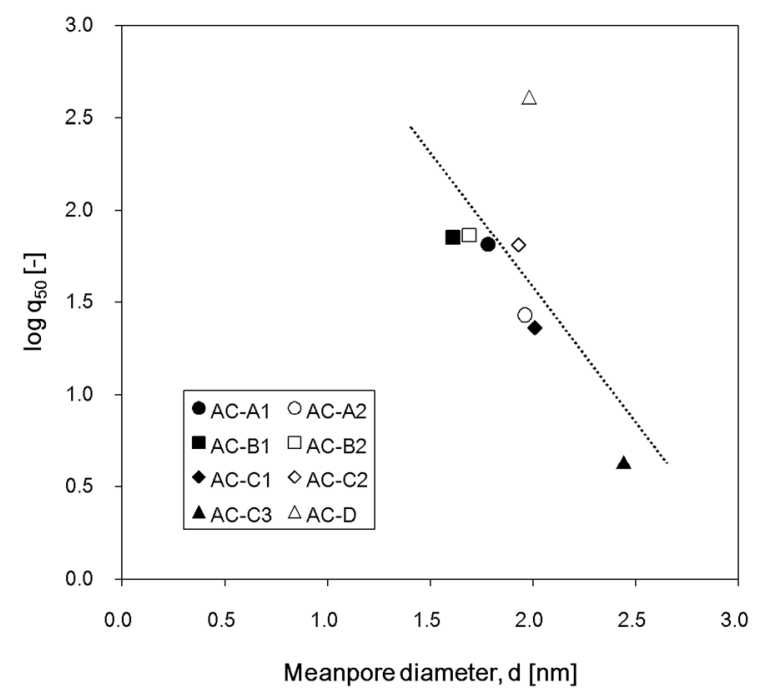

Fig. 3 - Correlation between the mean pore diameter of AC (d) and the amount of 1,4-dioxane adsorbed on ACs at $50 \mu \mathrm{g} / \mathrm{L}\left(\mathrm{q}_{50}\right)$. Dotted line shows Eq. (5). 
demonstrates a relatively strong correlation between $\mathrm{C}_{\text {aso }}$ and $\log \mathrm{q}_{50}$. Similarly, the following equation was obtained by a least squares fit to analyze the effect of $\mathrm{C}_{\mathrm{n}}$.

$$
\log \mathrm{q}_{50}=-5.3 \mathrm{C}_{\mathrm{n}}+2.8 \quad \text { (correlation coefficient, } \mathrm{R}=-0.776 \text { ) }
$$

The relationship and Eq. (7) are shown in Fig. 5. The value of the correlation coefficient also demonstrates a relatively strong correlation between $C_{n}$ and $\log q_{50}$. Both correlation coefficients were negative; the amount of adsorbed DOX decreased as $\mathrm{C}_{\text {aso }}$ or $\mathrm{C}_{\mathrm{n}}$ increased.

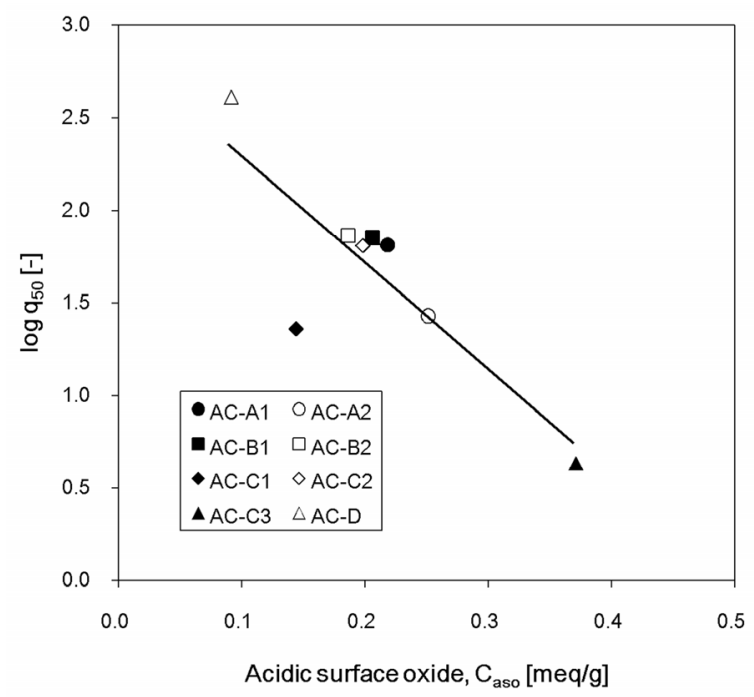

Fig. 4 - Correlation between the acidic surface oxide of $\mathrm{AC}\left(\mathrm{C}_{\mathrm{aso}}\right)$ and the amount of 1,4-dioxane adsorbed on ACs at $50 \mu \mathrm{g} / \mathrm{L}\left(\mathrm{q}_{50}\right)$. Solid line shows Eq. (6).

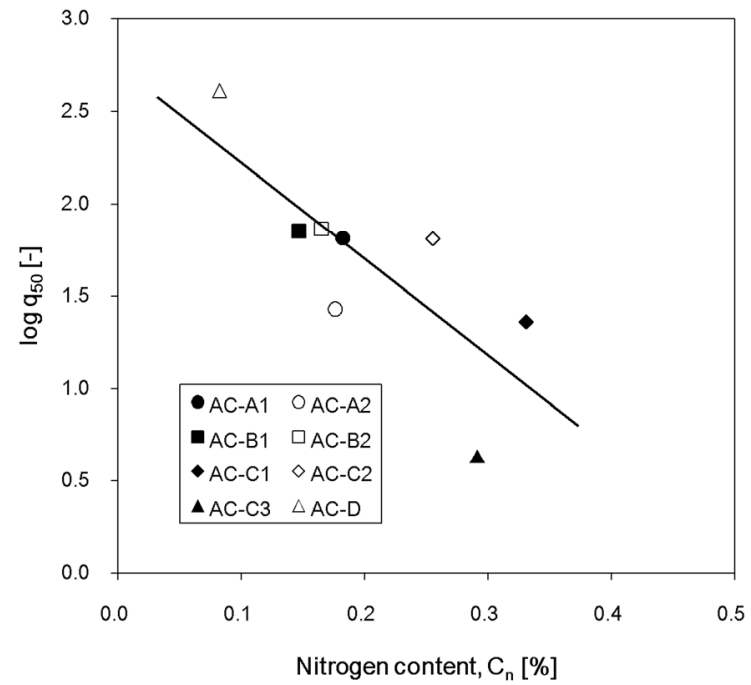

Fig. 5 - Correlation between the nitrogen content of $A C\left(C_{n}\right)$ and the amount of 1,4-dioxane adsorbed on ACs at $50 \mu \mathrm{g} / \mathrm{L}\left(\mathrm{q}_{50}\right)$. Solid line shows Eq. (7). 
In general, the presence of acidic carbon-oxygen surface functional groups, like the acidic surface oxides present in this study, makes the carbon surface hydrophilic and polar in character (Bansal and Goyal, 2005). Numerous studies have shown that increases in the oxygen or acidic functional group contents of AC impair the adsorption of organic compounds from aqueous solutions (e.g. Karanfil and Kilduff, 1999).

Carbon oxidation reduces the dispersive adsorption potential by decreasing the $\pi$-electron density in the graphene layers (Radovic, 1998). This is consistent with the preferential adsorption of water on carbon surfaces containing oxygen groups (Franz et al., 2000). Surface oxides including oxygen atoms are strongly interacting with water molecules, which are solvent because of the hydrogen bonding, and water molecules tend to cluster together. These clusters may interfere with the access to the hydrophobic moiety $\left(-\mathrm{CH}_{2}-\mathrm{CH}_{2}-\right)$ of the DOX molecule on the carbon surface. Also, when a DOX molecule adsorbs on a micropore surface, the already adsorbed water molecules have to be removed, which is more difficult as the surface hydrophilicity is stronger (Pendleton and Wong, 1997). Few studies have been reported on the effects of AC microporosity and/or surface chemistry on the adsorption of hydrophilic compounds such as DOX at trace concentration in water. The less hydrophilic carbons adsorb more 2-methylisoborneol (MIB), which contains 11 carbon atoms and 1 oxygen atom (Pendleton and Wong, 1997). A similar tendency was observed in the results obtained in this study concerning both $\mathrm{C}_{\text {aso }}$ and $\mathrm{C}_{\mathrm{n}}$.

The type of nitrogen-containing functional groups formed on $\mathrm{AC}$ remains unclear; a nitrogen atom is more electronegative than a carbon atom, similar to an oxygen atom (Alfarra et al., 2004). Water molecules tend to be adsorbed onto the polar atoms. The AC surface apparently becomes more hydrophilic because of this interaction and impairs hydrophobic adsorption of DOX. In the case of tertiary-butyl ether and trichloroethene, adsorbability decreased with an increase in the hydrophilicity of AC, assuming that hydrophilicity was the sum of oxygen and nitrogen, as analyzed by the elemental analysis (Li et al., 2002).

The value of $\mathrm{q}_{50}$ on AC-D was considerably greater than others. The $\mathrm{C}_{\mathrm{aso}}$ and $\mathrm{C}_{\mathrm{n}}$ values of AC-D were found to be the smallest of all the AC tested in this study. This suggests that the interference with water molecules adsorbed onto hydrophilic groups was extremely small. When hydrophilic groups are present around the entrance of a micropore, those water molecules may interfere as DOX approaches the micropore. Micropore volume available for the adsorption of DOX might increase with a decrease in the hydrophilicity of the AC surface. The value of $\mathrm{q}_{50}$ of AC-D was $410 \mu \mathrm{g} / \mathrm{g}$, which is equivalent to approximately $0.4 \mu \mathrm{L} / \mathrm{g}$. Consequently, an increase in the micropore volume might occur easily. Concerning the relationship between $\log \mathrm{q}_{50}$ and $\mathrm{d}$, the whole correlation coefficient shown in Eq. (5) was not so high, but it was considerably higher after recalculation, except for AC-D. The absorption of DOX onto AC-D could be an explanation for the results obtained in this study. It was assumed that the main factor for the adsorption of the hydrophilic compound (DOX) at trace concentration in water was surface chemistry rather than microporosity of AC. 


\section{CONCLUSIONS}

In this study, the adsorption behavior of DOX in water onto eight different ACs was studied. All adsorption isotherms obtained were found to fit a Freundlich equation. The index of adsorbability, $\mathrm{q}_{50}$, for AC-D was $410 \mu \mathrm{g} / \mathrm{g}$. This was markedly high in comparison with the other activated carbons, which showed $\mathrm{q}_{50}$ values in the range of $4.3-71.1 \mu \mathrm{g} / \mathrm{g}$. No practical influence of $\mathrm{S}$ on the adsorption of DOX was found. We observed that $\log \mathrm{q}_{50}$ mostly decreased linearly with an increase in $\mathrm{d}$. The concentrations of acidic surface oxides and nitrogen in the ACs affected the hydrophilicity of the adsorbent and impaired $\mathrm{q}_{50}$. Although DOX is a hydrophilic organic compound, the adsorption force between DOX and AC is mainly derived from the London dispersion force, similar to that causing the adsorption of common hydrophobic compounds. It was assumed that the main factor for the adsorption of DOX at trace concentration in water was surface chemistry rather than the microporosity of AC.

\section{REFERENCES}

Abe I., Hayashi K., Hirashima T., Kitagawa M. and Kuroki N. (1983a) Adsorptive property of hydrophobic porous adsorbents and their surface area and pore volume, J. Colloid Interface Sci., 93, 572.

Abe I., Hayashi K., Hirashima T., Kitagawa M. and Kuroki N. (1983b) Prediction of adsorbabilitiy of organic compounds from aqueous solution on activated carbon by means of the linear free-energy relationship, Bull. Chem. Soc. Jpn., 56, 1002-1005.

Abe I., Hayashi K., Tatsumoto H., Kitagawa M. and Hirashima T. (1985) The relation between activated carbon adsorption and water quality indexes, Water Res., 19, 1191-1193.

Abe I., Fukuhara T., Maruyama J., Tatsumoto H. and Iwasaki S. (2001) Preparation of carbonaceous adsorbents for removal of chloroform from drinking water, Carbon, 39, 1069.

Alfarra A., Frackowiak E. and Beguin F. (2004) The HSAB concept as a means to interpret the adsorption of metal ions onto activated carbons, Appl. Surf. Sci., 228, 84-92.

Bansal R. C. and Goyal M. (2005) Activated carbon adsorption, CRC Press, Boca Raton, FL, USA.

Boehm H. P. (1994) Some aspects of the surface chemistry of carbon blacks and other carbons, Carbon, 32, 759-769.

Dobbs R. A. and Cohen J. M. (1980) Carbon adsorption isotherms for toxic organics, EPA-600-8/80-023, United States Environmental Protection Ageny, Cincinnati, USA.

Franz M., Arafat H. A. and Pinto N. G. (2000) Effect of chemical surface heterogeneity on the adsorption mechanism of dissolved aromatics on activated carbon, Carbon, 38(13), 1807-1819.

Furuya E. G., Chang H. T., Miura Y. and Noll K. E. (1997) A fundamental analysis of the isotherm for the adsorption of phenolic compounds on activated carbon, Sep. Purif. Technol., 11, 69-78.

Iwasaki S., Fukuhara T., Abe I., Yanagi J., Mouri M., Iwashima Y., Tabuchi T. and Shinohara O. (2002) Adsorption of alkylphenols onto microporous carbons prepared from coconut shell, Synth. Met., 125, 207-211.

Karanfil T. and Kilduff J. E. (1999) Role of granular activated carbon surface chemistry 
on the adsorption of organic compounds. 1. Priority pollutants, Env. Sci. Tech., 33(18), 3217-3224.

Li L., Quinlivan P. A. and Knappe D. R. U. (2002) Effects of activated carbon surface chemistry and pore structure on the adsorption of organic contaminants from aqueous solution, Carbon, 40, 2085-2100.

Noll K.E., Gounaris V. and Hou W. S. (1992) Adsorption technology for air and water pollution control, Lewis Publishers, Inc., Chelsea, MI, USA.

Pendleton P. and Wong S. H. (1997) Properties of activated carbon controlling 2-methylisoborneol adsorption, Carbon, 35(8), 1141-1149.

Radovic L. R. (1998) Adsorption of organics from aqueous solution on surface-modified active carbons: A critical review, TANSO, 185, 326-331. 